\title{
Effects of an Anxiogenic Benzodiazepine Receptor Ligand on Motor Activity and Dopamine Release in Nucleus Accumbens and Striatum in the Rat
}

\author{
Nils Brose, , ${ }^{1, a}$ Robert D. O'Neill, ${ }^{2}$ Martyn G. Boutelle, ${ }^{1}$ Shelagh M. P. Anderson, ${ }^{1, b}$ and Marianne Fillenz ${ }^{1}$ \\ University Laboratory of Physiology, Oxford OX1 3PT, UK, and '2Department of Chemistry, University College, Belfield, \\ Dublin 4, Ireland
}

The effects of the anxiogenic $\beta$-carboline FG $7142(N$-methyl- $\beta$-carboline-3-carboxylate) on motor activity and dopamine release in nucleus accumbens and striatum were measured in the rat. Changes in extracellular homovanillic acid (HVA) concentration, monitored by computer-controlled linear sweep voltammetry with carbon-paste electrodes, were used as an index of changes in dopamine release. An intraperitoneal injection of FG 7142 was followed by an inhibition of the nocturnal rise in motor activity and in dopamine release in nucleus accumbens, but not striatum. Two days after the drug injection, dopamine release in nucleus accumbens returned to control level and then increased on days 3-6 after the injection; there was no delayed change in motor activity or in striatal dopamine release. In parallel experiments using ex vivo changes in the ratio of 3,4-dihydroxyphenylacetic acid (DOPAC) to dopamine as an index of changes in dopamine turnover, a similar early depression and delayed increase of dopamine turnover in nucleus accumbens, with no change in striatum, was found after an intraperitoneal injection of FG 7142. Regression analysis of motor activity versus dopamine release showed a decrease in correlation between these 2 parameters for nucleus accumbens but not striatum after FG 7142 injection. These results suggest that the inverse benzodiazepine receptor agonist FG 7142 has a biphasic effect on dopamine release from mesolimbic neurons and support the hypothesis that dopamine release in nucleus accumbens and striatum has a modulatory effect on the control of motor activity but does not play a determining role in the regulation of movement.

At present, the functional role of the mammalian striatum and nucleus accumbens, and their involvement in the regulation and initiation of movement, is not clear. Both structures receive major dopaminergic inputs from the midbrain (Ungerstedt,

\footnotetext{
Received Dec. 17, 1986; revised Mar. 18, 1987; accepted Mar. 18, 1987.

We thank the MRC for financial support, Ferrosan, Copenhagen, for the gift of FG 7142, and Hoffman-LaRoche Co., Basel, for Ro 15-1788. R.D.O'N. acknowledges a travel grant from The Royal Society and The Royal Irish Academy. N.B. receives tinancial support from The Queen's College, Oxford, and the E.P. Abraham Cephalosporin Fund.

Correspondence should be addressed to Dr. Marianne Fillenz, University Laboratory of Physiology, Parks Road, Oxford OX1 3PT, UK.

a Present address: Max Planck Institute for Psychiatry, Department of Neurochemistry, Am Klopferspitz 18A, D-8033 Planegg-Martinsried, FRG.

' Prescnt address: MRC Unit Clinical Pharmacology, Radcliffe Infirmary, Woodstock Road, Oxford OX2 6HE, UK.

Copyright (C 1987 Society for Neuroscience $0270-6474 / 87 / 092917-10 \$ 02.00 / 0$
}

1971), and the importance of dopamine in the striatum for motor control is demonstrated by the movement disorders that result from neurotoxic lesions of nigrostriatal dopamine neurons (Makanjuda and Ashcroft, 1982) and by the degeneration of these neurons found in Parkinson's disease in humans (Da Prada et al., 1984). However, the substantia nigra pars compacta cells show little variation in discharge frequency during changes in motor activity in either the cat (Trulson et al., 1981) or the rat (Miller et al., 1983); this has led to the suggestion that dopamine in the striatum acts as a neuromodulator with a tonic action, rather than as a classical transmitter (McGeer et al., 1984).

The nucleus accumbens has recently been described as an "interface" between the limbic system and the extrapyramidal motor system as it receives inputs from the hippocampus, the amygdala, and thalamic nuclei (Swanson and Cowan, 1973, 1977; Powell and Leman, 1976; Groenwegen et al., 1980; Kelley and Domesick, 1982; Kelley and Stinus, 1984) and projects to the striatum, the globus pallidus, and the substantia nigra (Conrad and Pfaff, 1976; Powell and Leman, 1976; Williams et al., 1977; Nauta et al., 1978). A dense dopaminergic input to the nucleus accumbens originates in the ventral-tegmental area (VTA) A10 cell group (Dahlström and Fuxe, 1965; Ungerstedt, 1971), and pharmacological, behavioral and electrophysiological experiments suggest that dopaminergic transmission in the nucleus accumbens plays a role in the initiation of movement and in goal-directed behavior (Mogenson and Yim, 1981; Neill and Justice, 1981). Thus, injection of dopamine agonists into the nucleus accumbens produces strong locomotor activation (Jackson et al., 1975; Makanjuda et al., 1980) while (systemic) $d$-amphetamine-induced locomotor activation, which is thought to be mediated by an increase in dopamine transmission in the nucleus accumbens (Kelly et al., 1975; Pijnenburg et al., 1976; Costall et al., 1977), is antagonized by neuroleptics microinjected into the nucleus accumbens (Jackson et al., 1975; Pijnenburg et al., 1975). In contrast, dopamine agonists injected locally into the striatum induce stereotyped behaviors (Costall et al., 1979). The release of dopamine in nucleus accumbens and in striatum seems, therefore, to play different roles in the regulation of motor activity.

Further functional differences between these 2 dopaminergic pathways are demonstrated by their differential responses to stress. The mesolimbic dopaminergic system responds to stress with an increase in dopamine turnover, which is blocked by benzodiazepines (BDZ) (Fadda et al., 1978; Watanabe, 1984). In contrast, the nigrostriatal dopaminergic system is unaffected by stress (Lavielle et al., 1978). 
FG 7142 is representative of a class of non-BDZ agents that binds to brain $\mathrm{BDZ}$ receptors but lacks the anticonvulsant and anticonflict (anxiolytic) effects of BDZs; instead, it produces opposite effects, which were interpreted as anxiety in both rat (Corda et al., 1983; Petersen and Jensen, 1984; Drugan et al., 1985) and man (Dorow et al., 1983). Tam and Roth (1985) reported increased mesocortical dopamine turnover after FG 7142, an effect similar to stress and opposite to BDZs (Fadda et al., 1978; Lavielle et al., 1978). However, both the BDZ and anxiogenic $\beta$-carbolines have similar depressant effects on motor activity in rodents (File et al., 1985; Little, 1986). It is likely that the effects of BDZs and $\beta$-carbolines on motor activity are mediated by different mechanisms and that, according to current theories of anxiety (Gray, 1978, 1981), the depressant effect of the anxiogenic $\beta$-carbolines might reflect behavioral inhibition rather than sedation (Little, 1986).

Because of the technical difficulties of monitoring changes in the release of neurotransmitters in behaving animals, little is known about the relationship between changes in transmitter turnover and associated changes in behavior. Among the techniques designed to detect changes in the chemical composition of brain extracellular fluid in vivo (Marsden, 1984), computercontrolled linear sweep voltammetry with chronically implanted carbon-paste electrodes is one of the electrochemical methods now available (O'Neill et al., 1983a, b). This method is suitable for the continuous monitoring, over a long period of time, of changes in the extracellular concentration of the dopamine metabolite homovanillic acid (HVA) in freely moving rats. Changes in this signal can be used, under certain conditions, as an index of dopamine release (O'Neill and Fillenz, 1985a, b; Fillenz and O'Neill, 1986).

The measurement of changes in the ratio of 3,4-dihydroxyphenylacetic acid (DOPAC) to dopamine is another widely used technique for measuring changes in dopamine turnover (Fadda et al., 1978; Lavielle et al., 1978; Dunn and File, 1983).

We have used ex vivo determination of DOPAC/dopamine (DA) ratios and in vivo voltammetry with parallel monitoring of motor activity to study the effect of FG 7142 on motor activity and on dopamine release in nucleus accumbens and striatum, and have analyzed the relation between the changes in these parameters in an attempt to gain further insight into the role of dopamine release in these 2 brain areas in the control of motor activity.

\section{Materials and Methods}

In vivo studies. Carbon-paste working electrodes were prepared and implanted as described previously (O'Neill et al., 1982). In brief, carbon paste $(2.8 \mathrm{gm}$ carbon powder per $1 \mathrm{ml}$ silicone oil) was packed into 300 $\mu \mathrm{m}$ (o.d.) Teflon-coated silver wire.

Sixteen male Sprague-Dawley rats $(270-350 \mathrm{gm})$ were stereotaxically implanted, under chloral hydrate anesthesia $[7 \mathrm{ml} / \mathrm{kg}, 5 \%$ (wt/vol) solution, i.p.], with these electrodes; silver wires, placed in the cortex, were used for the reference (O'Neill et al., 1983c) and auxiliary electrodes. The coordinates, with the head level between bregma and lamb$\mathrm{da}$, were as follows: nucleus accumbens, AP 1.5 (from bregma), L 1.5 (from bregma), DV 7.0 (from skull); striatum, AP -0.5, L 2.7, DV 4.8 (König and Klippel, 1963). All rats were implanted with 2 working electrodes, either in the left nucleus accumbens and the right striatum or bilaterally in nucleus accumbens or striatum. The position of the electrodes was verified histologically after the experiment.

The animals were given 2-3 d to recover after surgery before being placed in the recording cages and connected to the microcomputercontrolled equipment (O'Neill et al., 1983b). Linear sweep voltammograms between 0 and $650 \mathrm{mV}$ were recorded at 12 min intervals at a rate of $5 \mathrm{mV} / \mathrm{sec}$. The background current for each electrode was measured in situ before each experiment, as described previously $\left(\mathrm{O}^{\prime}-\right.$ Neill et al., 1983a). Following subtraction of the background current, the voltammograms consisted of 3 peaks. Peak 1 was due to the oxidation of ascorbic acid (O'Neill et al., 1983b), peak 2 to uric acid (O'Neill et al., 1984; Mueller et al., 1985), and the dopamine metabolite HVA was responsible for peak 3 (O'Neill and Fillenz, 1985a). The size of this peak was measured as its height above the baseline ( $\mathrm{O}^{\prime}$ Neill and Fillenz, 1985a); changes in the height of this peak were proportional to changes in the concentration of HVA around the electrode tip.

Between the electrochemical recordings (of approximately $9 \mathrm{~min}$ duration), the total motor activity of each rat was monitored using a Doppler-shift microwave device linked to the parallel port of the computer interface (O'Neill and Fillenz, 1985a). The lighting in the windowless room, also controlled by the computer, was on a $12 \mathrm{hr} / 12 \mathrm{hr}$ light/dark cycle, with lights on from 08.00 to 20.00 hours.

Once connected to the equipment, the rats were given a further $3 \mathrm{~d}$ to get used to the recording cages and to allow the electrodes to equilibrate. Recording started after this settling-down period and continued for $11 \mathrm{~d}$. On day 1 the rats were undisturbed. At the end of the light period of day 2 (20.00 hours), an injection of $0.5 \mathrm{ml}$ vehicle [one drop Tween 80 (DIFCO, West Molesey, UK) in $10 \mathrm{ml}$ distilled water, i.p.] was given. After a second undisturbed day (day 3), FG 7142 (Ferrosan, Copenhagen, Denmark; $10 \mathrm{mg} / \mathrm{kg}$ in $0.5 \mathrm{ml}$ vehicle, i.p.) was administered at the end of the light period of day 4 (20.00 hours) and recording continued for a further $7 \mathrm{~d}$ (days 5-11) without injection.

The nocturnal increase in motor activity was taken as the difference between the mean number of moves for the light and dark periods. The difference between the mean HVA signal for the light and dark periods, expressed as a percentage of the value for the light period, was used to quantify nocturnal changes in HVA levels.

To examine the acute effect of FG 7142 on the nocturnal increase in motor activity and HVA signals, segments of the recording period were compared. To study the drug effect on motor activity, these segments were chosen as follows: $12.00-20.00$ hours for the light segment, 20.00 22.00 hours for the dark segment. Corresponding segments for the HVA data were 18.00-20.00 hours for the light segment and 20.30-21.30 hours for the dark segment. Longer segments for the motor activity recordings were chosen in order to eliminate the considerable fluctuations in movement.

Normalized plots of circadian motor activity were obtained by expressing each value as a percentage of the mean motor activity for the $24 \mathrm{hr}$ recording. The data from the different rats were then averaged for each day and the mean percentage values were reconverted to mean absolute values. Normalized plots of circadian recordings of HVA signals were obtained using the same procedure.

To analyze in more detail the effect of FG 7142 on the relation between motor activity and the HVA signals, regression analyses between these variables were carried out for a corresponding segment of the recordings (16.00-24.00 hours, 40 points). For this purpose, a weighted moving average of the original data was calculated to reduce the fluctuations inherent in recording small currents $(<1 \mathrm{nA})$ and to clarify the systematic relationships between the variables. Because changes in extracellular HVA concentration lag behind changes in motor activity, a cross-correlation analysis was performed (O'Neill and Fillenz, 1985a); the highest correlation occurred when the motor activity data were shifted by $40 \pm$ 4 or $48 \pm 8$ min with respect to the HVA data in nucleus accumbens or striatum, respectively.

Student's $t$ test for paired observations was used in all statistical analyses unless otherwise stated. To allow paired comparison with the control data, the data for the 2 control days (days 1 and 3 ) were averaged for each rat (motor activity) or each electrode (HVA signals). Values of $n$ refer to number of rats (motor activity) and number of electrodes (HVA signals) or, when stated, to number of determinations (rats $\times$ days, electrodes $\times$ days); $p<0.05$ was considered significant.

Ex vivo studies. Male Sprague-Dawley rats weighing $200-250 \mathrm{gm}$ were used for all ex vivo experiments.

To assay nocturnal changes in the HVA/DA and DOPAC/DA ratios, littermates were killed at either 16.00 or 23.00 hours by pncumothoracic shock followed by decapitation. Brains were quickly removed and placed on ice. The brain areas were dissected out according to the method of Westerink and Korf $(1975,1976)$ and homogenized in $2 \mathrm{ml}$ perchloric acid. The homogenate was spun at $1000 \times g$ for 15 min using a MSE super minor centrifuge. The supernatant was removed and stored at $-20^{\circ} \mathrm{C}$.

To study the effect of FG 7142 on DOPAC/DA ratios, littermates 
A

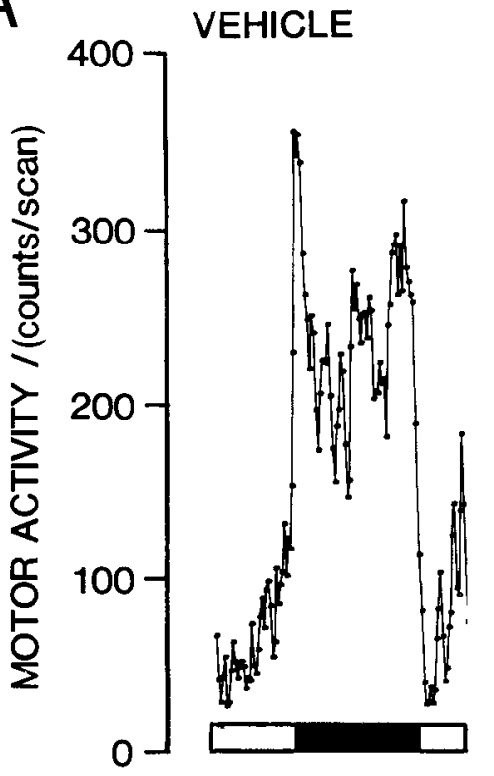

B

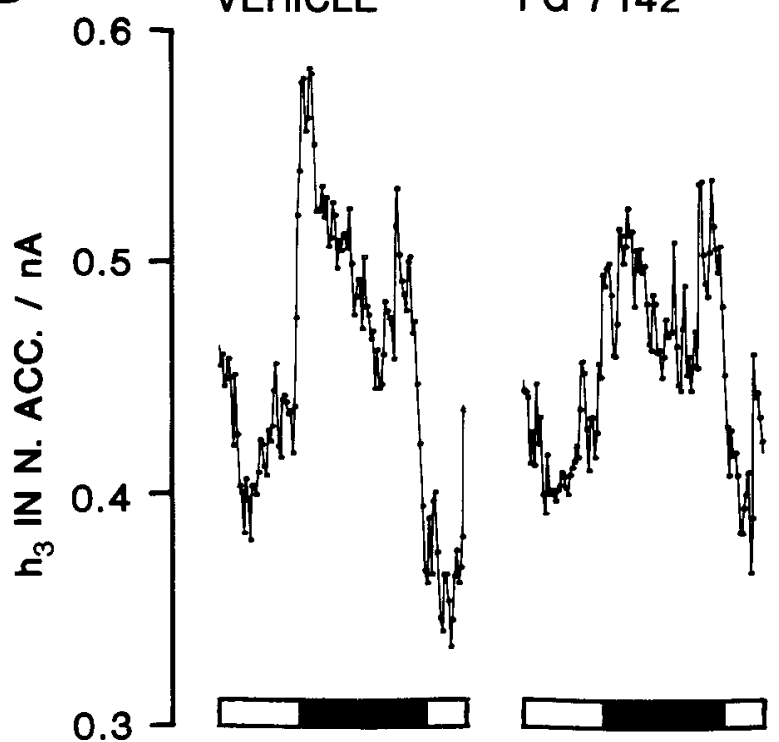

FG 7142

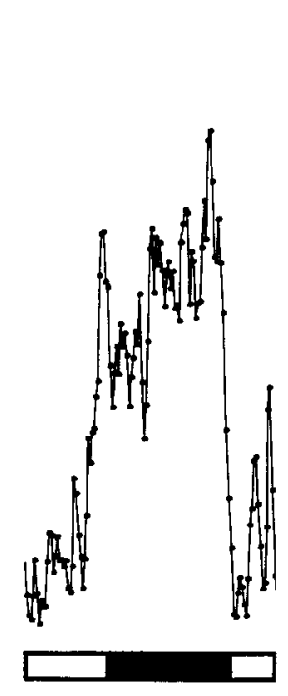

CONTROL

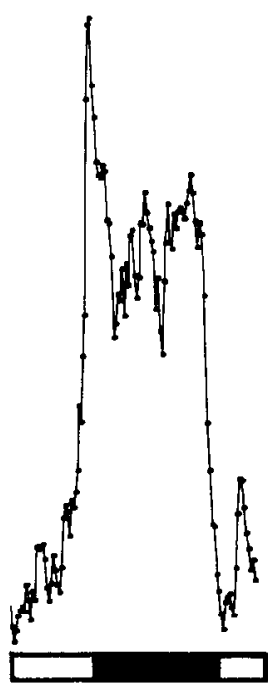

CONTROL

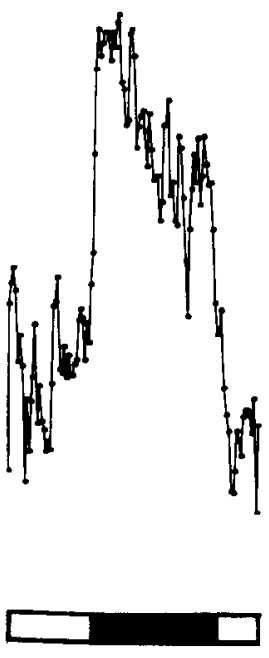

Figure 1. The circadian pattern of motor activity $(A)$ and HVA signal in nucleus accumbens $(B)$ under control conditions, and for vehicle injection and FG 7142 injection. Black bars indicate dark periods of the light/dark cycle. Injections of vehicle $(0.5 \mathrm{ml}$ distilled water + Tween 80, i.p.) or FG $7142(10$ $\mathrm{mg} / \mathrm{kg}$ in $0.5 \mathrm{ml}$ vehicle, i.p.) were given at the beginning of the dark period. Figures represent means of 15-30 $(A)$ or 14-28 $(B)$ determinations. For clarity, error bars are not shown. The immediate nocturnal increase in both motor activity and HVA signal in nucleus accumbens was reduced by FG 7142 (see also Fig. 2). were injected with either $0.5 \mathrm{ml}$ vehicle (one drop Tween 80 in $10 \mathrm{ml}$ distilled water, i.p.) or FG $7142(10 \mathrm{mg} / \mathrm{kg}$ in $0.5 \mathrm{ml}$ vehicle, i.p.) and killed $30 \mathrm{~min}, 1 \mathrm{hr}, 24 \mathrm{hr}$, or $4 \mathrm{~d}$ after the injections. In separate experiments designed to examine whether the acute effect of FG 7142 was mediated by central $\mathrm{BDZ}$ receptors and could be blocked by the imidazodiazepine Ro 15-1788 (flumazepil; Hoffman-LaRoche Co., Basel, Switzerland), a specific BDZ receptor blocker, animals received 2 injections at a time interval of $10 \mathrm{~min}$ and were killed $30 \mathrm{~min}$ after the second injection. For this purpose animals were treated in 4 groups: the Vehicle Control group $-0.5 \mathrm{ml}$ vehicle, i.p., followed after $10 \mathrm{~min}$ by $0.5 \mathrm{ml}$ vehicle, i.p.; the FG 7142 group $-0.5 \mathrm{ml}$ vehicle, i.p., followed after $10 \mathrm{~min}$ by $10 \mathrm{mg} / \mathrm{kg}$ FG 7142 in $0.5 \mathrm{ml}$ vehicle, i.p.; the Ro 15 1788 group-20 mg/kg Ro $15-1788$ in $0.5 \mathrm{ml}$ vehicle, i.p., followed after $10 \mathrm{~min}$ by $0.5 \mathrm{ml}$ vehicle, i.p.; and the Ro $15-1788 / \mathrm{FG} 7142$ group - $20 \mathrm{mg} / \mathrm{kg}$ Ro $15-1788$ in $0.5 \mathrm{ml}$ vehicle, i.p., followed after 10 min by $10 \mathrm{mg} / \mathrm{kg} \mathrm{FG} 7142$ in $0.5 \mathrm{ml}$ vehicle, i.p. Brains were removed and areas dissected out and homogenized as described above. Supernatants of the homogenates were stored at $-20^{\circ} \mathrm{C}$

All samples were assayed within $24 \mathrm{hr}$ after the experiments by highperformance liquid chromatography (HPLC) with electrochemical detection. The HPLC system consisted of an ACS 300/02 scrics isocratic pump, a Rheodyne 7125 sample injection valve with a $50 \mu$ linjection loop, and a $15 \mathrm{~cm}$ Hypersil 3 ODS column with a $5 \mathrm{~cm}$ Co-Pel ODS guard column. The electrochemical detection unit consisted of a carbonpaste electrode at a potential of $500 \mathrm{mV}$ and an amperometric controller linked to a chart recorder (Pantos Unicorder U228). The mobile phase consisted of a citrate/acetate buffer containing $0.034 \mathrm{M}$ citric acid, 0.1 M NaOH, $0.185 \mathrm{~mm}$ octanesulfonic acid, $0.45 \%$ acetic acid, and $10 \%$ 


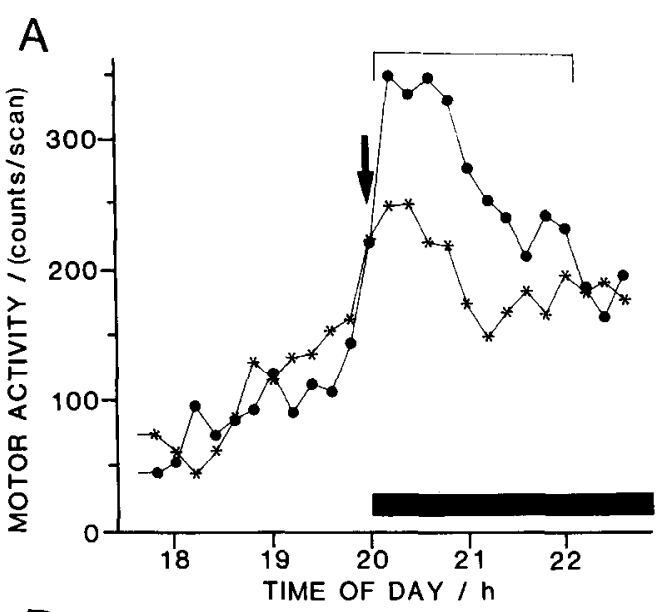

$\mathrm{B}$
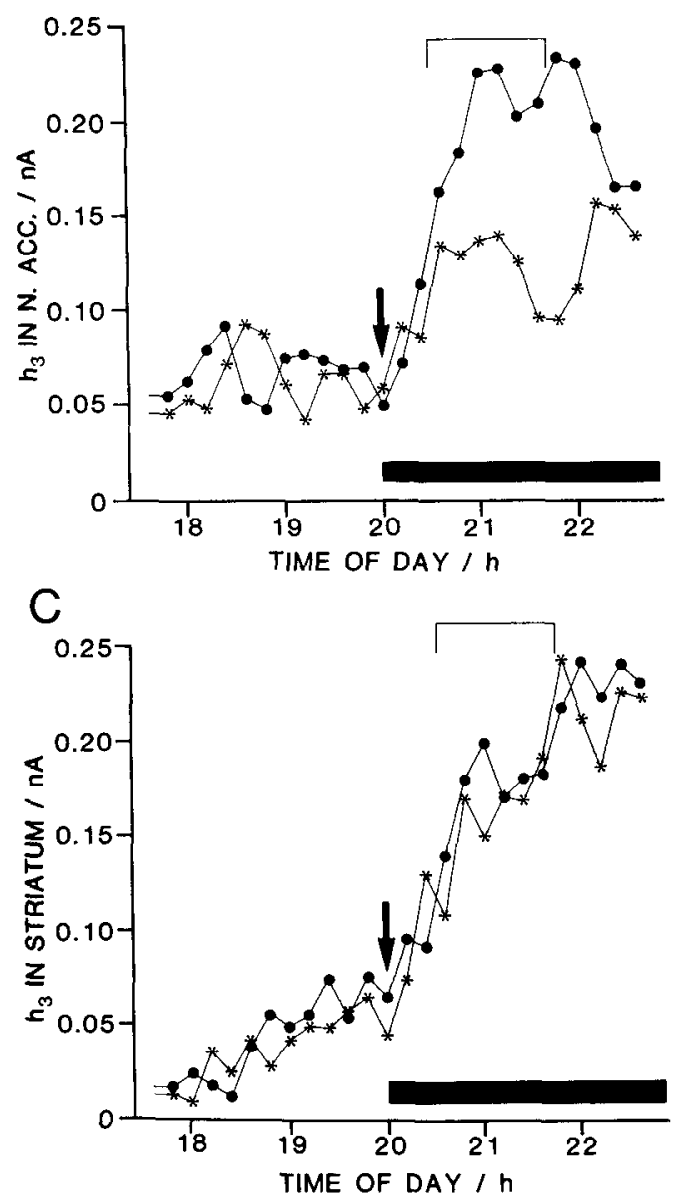

Figure 2. Segments of the circadian recordings of motor activity $(A)$ and HVA signals in nucleus accumbens $(B)$ and striatum $(C)$. Normalized plots for the days of vehicle injection (filled circles; $0.5 \mathrm{ml}$ distilled water + Tween 80, i.p.) and FG 7142 injection (asterisks; $10 \mathrm{mg} / \mathrm{kg}$ in $0.5 \mathrm{ml}$ vehicle, i.p.) are superimposed. Injection time is indicated by arrows. Black bars indicate dark periods of the light/dark cycle; square brackets indicate the period used for the segmental analysis. Figures represent means of $15(A), 14(B)$, or $5(C)$ determinations. For clarity, error bars are not shown.

methanol, adjusted to $\mathrm{pH} 4.6$ using glacial acetic acid.

Data from pairs of vehicle-injected and FG 7142-injected animals were compared using a paired Student's $t$ test. Values of $n$ refer to the number of pairs; $p<0.05$ was considered significant.

\section{Results}

In vivo studies

Circadian pattern. The normal motor activity of rats maintained under a $12 \mathrm{hr} / 12 \mathrm{hr}$ light $/$ dark cycle, as well as the HVA signals in nucleus accumbens and striatum, followed a circadian pattern that was characterized by low levels of activity and HVA concentration during the light period and long intervals of high motor activity accompanied by increased HVA levels during the dark periods. The average peak heights for the control period (days 1 and 3 ) were $0.48 \pm 0.05 \mathrm{nA}(n=28$ determinations) in nucleus accumbens and $0.39 \pm 0.06 \mathrm{nA}(n=10)$ in striatum.

Acute effect of $\mathrm{FG} 7142$. 'The injection of $\mathrm{FG} 7142(10 \mathrm{mg} /$ $\mathrm{kg}$, i.p.), given at the end of the light period, changed the circadian pattern of motor activity and HVA lcvels in nucleus accumbens, as shown in Figure 1. In the drug-injected rats, the abrupt rise in motor activity and HVA levels in nucleus accumbens, which was seen after vehicle injection as well as under control conditions, showed a marked reduction. Figure 1 suggests that the effect of the drug injection was brief and restricted to the early part of the dark period. To study this effect of FG 7142 in greater detail, a segment of the circadian recordings was examined as described in Materials and Methods. In Figure 2, segments of the normalized circadian plots of motor activity and HVA levels in nucleus accumbens and striatum are shown following vehicle and drug injection; the data are summarized in Table 1. Vehicle injection had no effect on the segmental nocturnal increase in motor activity (Fig. $2 A$ ); there was a $37 \pm$ $9 \%$ reduction in motor activity following FG 7142 injection as compared to after vehicle injection (Table 1). One day after the drug administration, values returned to control levels. Similar results were obtained for the HVA signals in the nucleus accumbens (Fig. 2B): Injection of vehicle was without effect; after injection of FG 7142 the segmental nocturnal rise in HVA levels was reduced by $55 \pm 19 \%$ (Table 1) and returned to control levels on the following day. Segmental nocturnal increases in striatal HVA levels did not change after either vehicle or drug administration (Fig. 2C; Table 1).

Delayed effect of $F G 7142$. Nocturnal increases in motor activity and HVA concentration, expressed as a percentage of the mean value over the first $3 \mathrm{~d}$ of the experiment, are shown in Figure 3. The mean decrease over the entire dark period following FG 7142 administration was $14 \pm 5 \%$ for motor activity and $33 \pm 20 \%$ for HVA in nucleus accumbens. The nocturnal increase in HVA levels in the nucleus accumbens returned to control level on day 6 ; on days $7-10$ it rose by $25 \pm 8 \%$ above the mean control value. The histogram in Figure $3 B$ shows the immediate decrease and delayed increase in the nocturnal rise in HVA levels following a single injection of FG 7142. There were no delayed changes in motor activity (Fig. $3 A$ ). The nocturnal rise in striatal HVA concentrations remained unchanged during the entire course of the experiment (Fig. 3C).

Correlation analysis between motor activity and HVA levels in nucleus accumbens and striatum. In order to study the relation between motor activity and HVA levels in nucleus accumbens and striatum in greater detail, regression analyses were carried out for the segment defined above. Correlation coefficients for motor activity versus HVA levels in nucleus accumbens and in striatum over the entire $11 \mathrm{~d}$ period are shown in Figure 4. The correlation coefficients for the striatal data did not change in the course of the experiment; the mean value for the correlation coefficient was $0.80 \pm 0.02(n=46)$. The correlation coefficient 


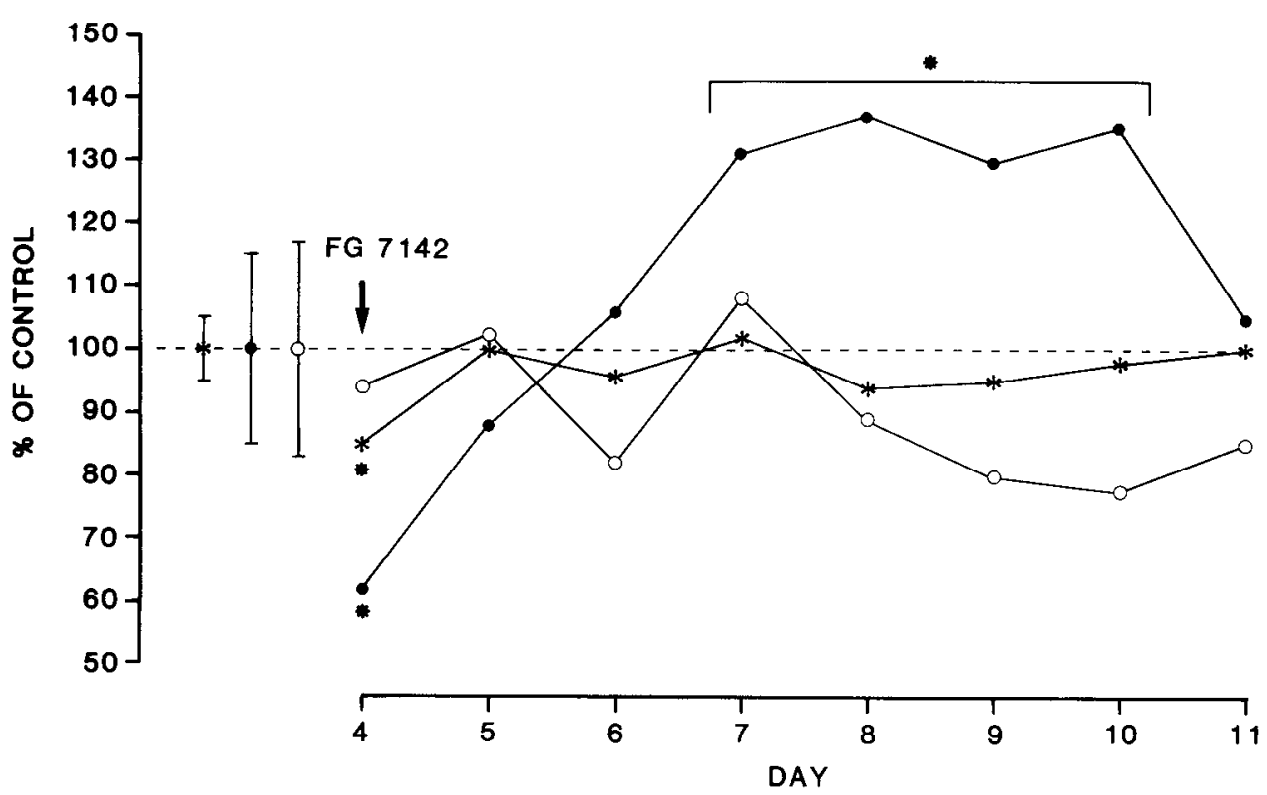

A

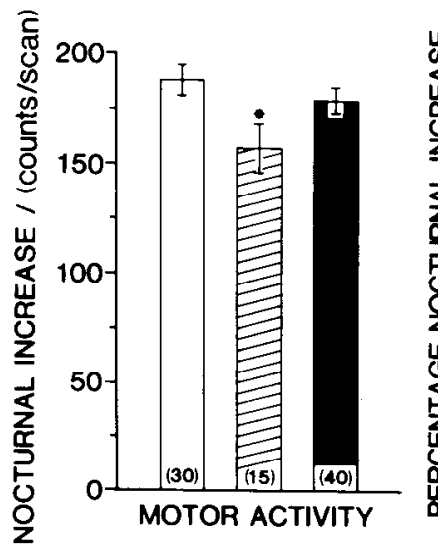

B

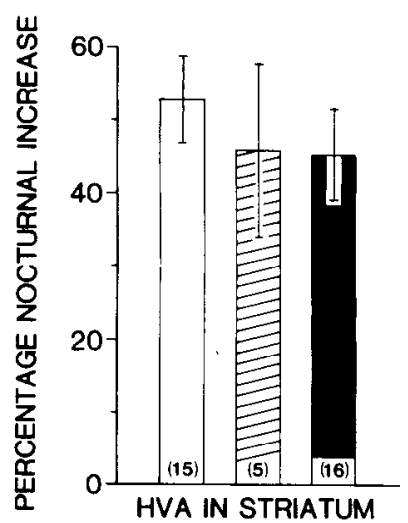

Figure 3. Nocturnal increases in motor activity ( $A$, and asterisks) and HVA lcvels in nucleus accumbens $(B$, and filled circles) and striatum ( $C$, and open circles). Nocturnal increases in motor activity were calculated as the difference in the mean number of counts/ 12 min scan for the light and dark periods. Nocturnal increases in HVA levels were calculated as the difference in the average peak heights of the light and dark periods, expressed as the percentage of the light level. Results for days 4-11 are given as the percentage of the value for the pooled data of control days ( 1 and 3 ) and the day of the vehicle injection (2). Each point represents the mean of 10-15 $(A), 8-14(B)$, or 4-5 $(C)$ determinations. For clarity, only the average SEM is shown. The histograms show the nocturnal increases in motor activity $(A)$ and HVA levels in nucleus accumbens $(B)$ and striatum $(C)$ in absolute figures. The data for days 1-3 (white), day 4 (FG 7142, cross-hatched) and days $7-10$ (black) are shown; $n$ values are given in parentheses. ${ }^{*} p<0.05$, compared to data for days $1-3$. for motor activity versus HVA levels in nucleus accumbens was unchanged after vehicle injection but was reduced by $33 \pm 7 \%$ after injection of FG 7142. On subsequent days, correlation coefficients returned to control value. There was no change in time shift for maximal correlation in the cross-corrclation analysis. This is illustrated for nucleus accumbens in Figure 5, in which correlation coefficients are plotted against time shift for vehicle- and drug-injected animals. The scatter plots illustrate

Table 1. Segmental nocturnal increases in motor activity and HVA levels in nucleus accumbens and striatum

\begin{tabular}{lllll} 
Day & Injection & $\begin{array}{l}\text { Motor activity } \\
\text { (counts/scan) }\end{array}$ & $\begin{array}{l}\text { HVA in n. acc. } \\
\text { (\% change) }\end{array}$ & $\begin{array}{l}\text { HVA in striatum } \\
\text { (\% change) }\end{array}$ \\
\hline $1+3$ & None & $255 \pm 9(n=30)$ & $31 \pm 4(n=28)$ & $30 \pm 11(n=10)$ \\
2 & Vehicle & $245 \pm 15(n=15)$ & $30 \pm 4(n=14)$ & $29 \pm 7(n=5)$ \\
4 & FG 7142 & $162 \pm 26(n=15)^{a, b}$ & $13 \pm 5(n=14)^{c, d}$ & $32 \pm 16(n=5)$ \\
5 & None & $242 \pm 8(n=15)$ & $25 \pm 4(n=14)$ & $27 \pm 14(n=5)$ \\
\hline
\end{tabular}

The segmental nocturnal increase in motor activity was calculated as the difference in the mean number of counts/12 min scan for a light segment (12.00-20.00 hours) and a dark segment (20.00-22.00 hours; see square bracket in Fig. $2 A$ ). The segmental nocturnal increase in HVA levels was calculated as the difference between the average peak heights for a light (18.0-20.00 hours) and a dark segment (20.30-21.30 hours; see square bracket in Fig. 2, B, C) expressed as the percentage of the light level. Data for the control days ( 1 and 3 ) were pooled. Errors indicate SEMs. ${ }^{a} p<0.01$, compared to mean control values; ${ }^{b} p<0.001$, compared to vehicle injection; ${ }^{c} p<0.05$, compared to mean control values; ${ }^{d} p<0.01$, compared to vehicle injection. 
Figure 4. Correlation coefficients for motor activity versus HVA levels in nucleus accumbens (filled circles) and striatum (open circles), calculated for a segment of the circadian recording (16.00-24.00 hours, 40 points). The days of vehicle injection and FG 7142 injection are indicated by arrows. Each point represents the mean of 6-10 (filled circles) or 4-5 (open circles) determinations. For clarity, only the average SEM is shown. ${ }^{*} p<0.05$, compared to mean control value and vehicle injection.

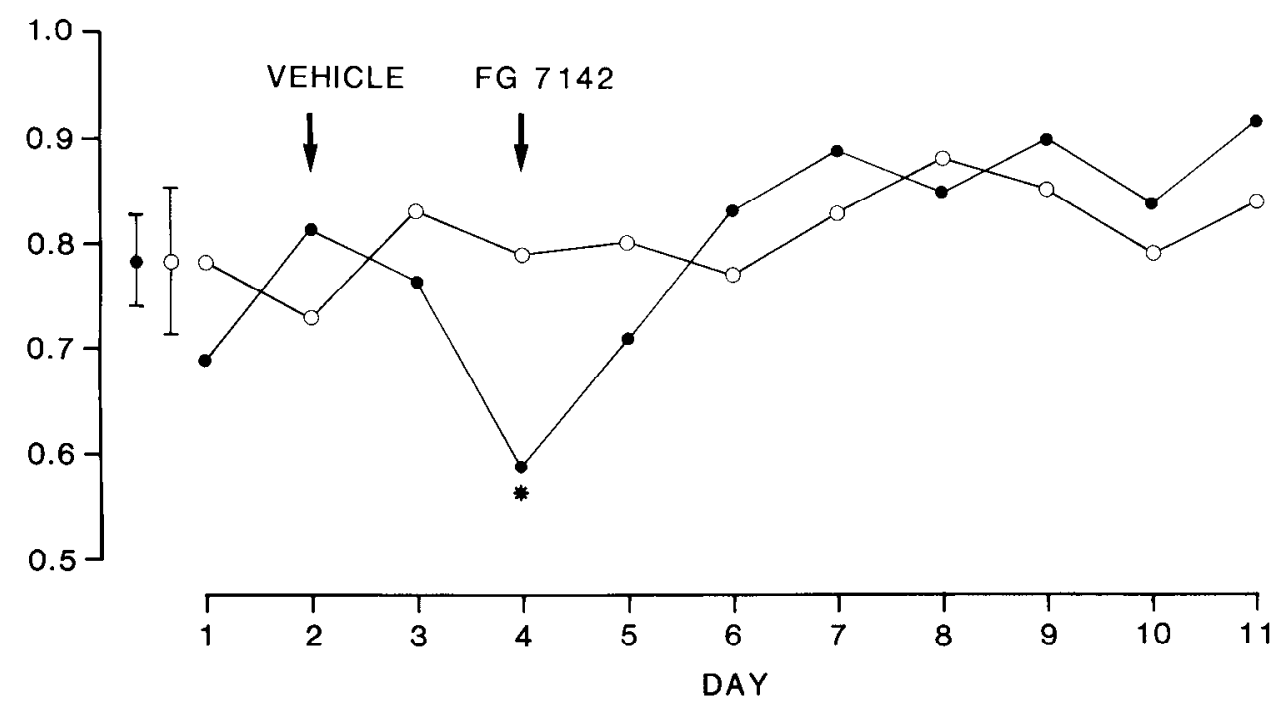

the relationship between motor activity and HVA peak heights in the nucleus accumbens following vehicle $(A)$ and FG 7142 $(B)$ injection. Open circles represent data of the preinjection period.

\section{Ex vivo studies}

To obtain a second, independent measure of the effects of FG 7142 on dopamine turnover, changes in the metabolite-to-transmitter ratio in nucleus accumbens and striatum were measured.

Nocturnal changes in metabolite ratios. Both HVA/DA and DOPAC/DA ratios were increased during the dark period in nucleus accumbens and striatum (Table 2). Nocturnal increases in $\mathrm{HVA} / \mathrm{DA}$ ratios were $18 \pm 6 \%$ in nucleus accumbens and $14 \pm 6 \%$ in striatum; the increases in DOPAC/DA ratios were $21 \pm 6 \%$ in nucleus accumbens and $15 \pm 3 \%$ in the striatum.

Effect of FG 7142 on DOPAC/DA ratios in nucleus accumbens and striatum. Since HVA/DA and DOPAC/DA ratios showed very similar nocturnal rises and DOPAC/DA ratios are more widely used, the latter metabolite ratio was used as the measure of changes in DA turnover. The changes in DOPAC/DA ratios in the nucleus accumbens after a single injection of FG 7142 were found to be biphasic: Animals killed $30 \mathrm{~min}, 1 \mathrm{hr}$, or 24 hr after a single injection of FG 7142 had reduced DOPAC/DA ratios, compared to vehicle-injected animals; $4 \mathrm{~d}$ after a single injection of $\mathrm{FG} 7142$, DOPAC/DA ratios were increased. In vehicle-injected rats DOPAC/DA ratios in the nucleus accumbens were significantly greater than in uninjected controls: Increases were $30 \pm 12 \% 30 \mathrm{~min}$ after the injection, $33 \pm 12 \% 1$ $\mathrm{hr}$ after the injection, and $51 \pm 14 \%(n=5) 24 \mathrm{hr}$ after the injection. There was no difference in DOPAC/DA ratios in the striatum between vehicle-injected and FG 7142-injected rats (Table 3 ) or between vehicle-injected and uninjected rats (not shown).

In a separate experiment, the effect of pretreatment of the rats with the specific BDZ receptor blocker Ro $15-1788(20 \mathrm{mg} / \mathrm{kg}$ in $0.5 \mathrm{ml}$ vehicle, i.p.) on the acute effect of FG 7142 on DOPAC/DA ratios was examined. This pretreatment completely blocked the effect of FG 7142 (see Table 4).

\section{Discussion}

In the present study we used 2 distinct but indirect methods to measure changes in dopamine release in nucleus accumbens and striatum following a single intraperitoneal injection of FG 7142. Evidence that the third peak in voltammograms obtained in nucleus accumbens and striatum using linear sweep voltammetry and carbon-paste electrodes represents extracellular HVA concentration, and that changes in this signal reflect changes in dopamine release, has been presented (O'Neill and Fillenz, 1985a, b; Fillenz and O'Neill, 1986). Previous experiments using voltammetry have demonstrated that both motor activity and IIVA concentration show very similar circadian changes (O'Neill and Fillenz, 1985b). Metabolite-to-transmitter ratios are widely used as a measure for dopamine turnover (Fadda et al., 1978; Lavielle et al., 1978; Dunn and File, 1983). The similarity in the values for the nocturnal increase of the metabolite/DA ratio, measured ex vivo, and HVA levels, measured in vivo using voltammetry, further validates these techniques and justifies their parallel use. However, changes in metabolite concentration after drug administration must be treated with caution since drugs may produce changes in the metabolite clearance rate (Commissiong,

Table 2. Nocturnal increases in DOPAC/DA and HVA/DA ratios in nucleus accumbens and striatum

\begin{tabular}{|c|c|c|c|c|c|c|}
\hline & \multicolumn{3}{|c|}{ Nucleus accumbens $(n=6)$} & Striatum $(n=8)$ & \multirow[b]{2}{*}{ Night } & \multirow[b]{2}{*}{$\%$ Change } \\
\hline & Day & Night & $\%$ Change & $\overline{\text { Day }}$ & & \\
\hline DOPAC/DA & $0.201 \pm 0.019$ & $0.251 \pm 0.018^{a}$ & $21 \pm 6$ & $0.170 \pm 0.005$ & $0.195 \pm 0.007^{c}$ & $15 \pm 3$ \\
\hline HVA/DA & $0.249 \pm 0.079$ & $0.282 \pm 0.077^{b}$ & $18 \pm 6$ & $0.119 \pm 0.021$ & $0.130 \pm 0.026^{b}$ & $14 \pm 6$ \\
\hline
\end{tabular}

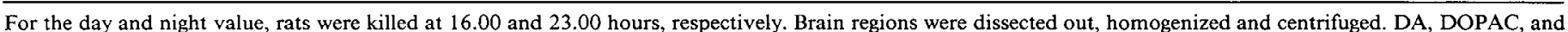

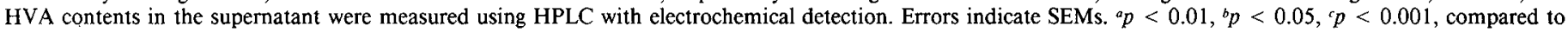
daytime values. 


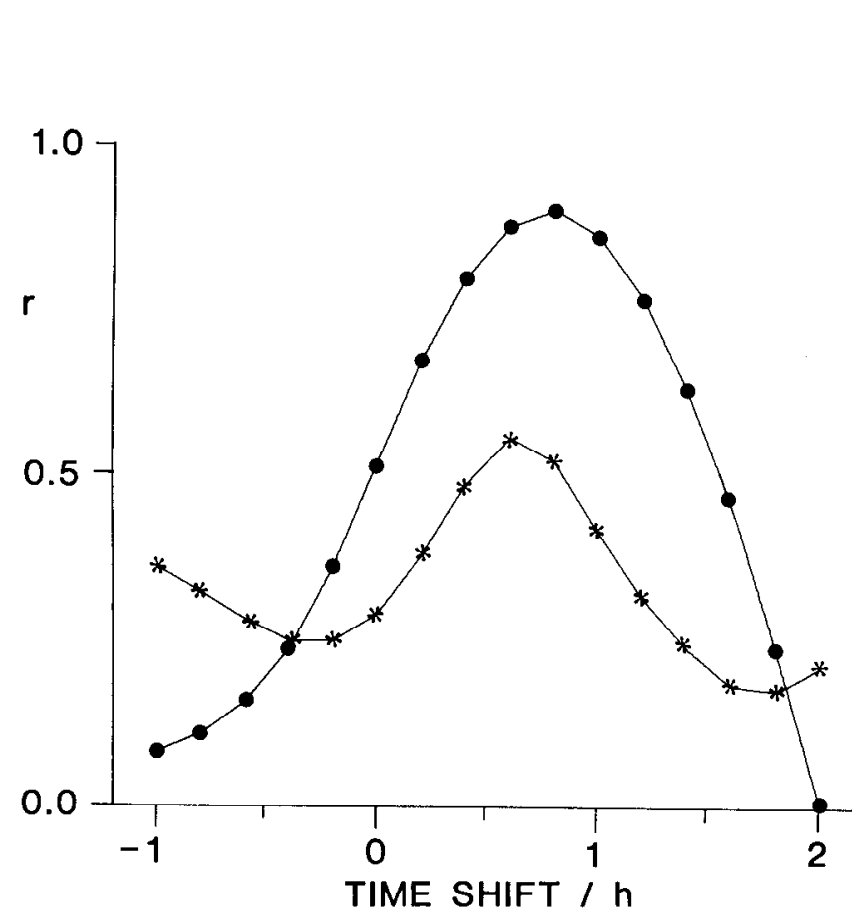

A

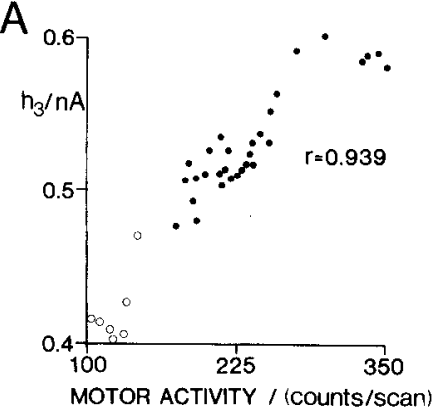

$\mathrm{B}$

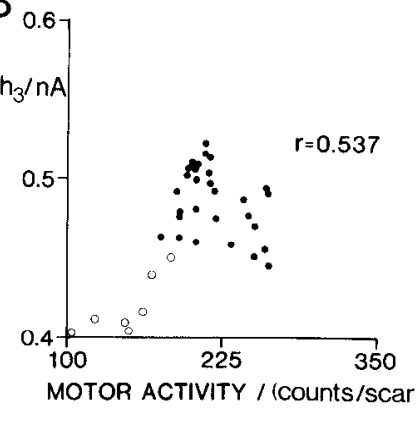

Figure 5. Cross-correlation analysis between the normalized circadian recordings of HVA levels in nucleus accumbens and motor activity for the day of vehicle injection (filled circles) and the day of the FG 7142 injection (asterisks) (see Fig. 1 for plots of the circadian recordings), calculated for a segment of the circadian recordings ( 16.00 24.00 hours, 40 points). Cross-correlation coefficients $(r)$ were calculated by comparing $m(t+x)$ with $h_{3}(t)$ (in the range $x=-5$ to $x=10 ; x$ is the number of scans taken at $12 \mathrm{~min}$ intervals), where $h_{3}(t)$ is the height of peak 3 at time $t$ and $m(t)$ is the value of the movement counter following that scan. The scatter plots in the insets refer to the optimal cross-correlation: $A$, vehicle injection; $B$, FG 7142 injection. Correlation coefficients are given. Open circles represent points of the preinjection period, filled circles points of the postinjection period.
1985; Westerink and Krickert, 1986). Since, in the present study, FG 7142 had different effects on metabolite levels in nucleus accumbens and striatum, the changes are unlikely to be attributable to an effect on metabolite clearance, as the anatomical proximity of the 2 brain areas suggests that their clearance mechanisms have similar characteristics.

The reduction in motor activity by a single intraperitoneal injection of FG 7142 confirms reports of other investigators (File et al., 1985; Little, 1986) and is compatible with the animal model of anxiety, in which behavioral inhibition is a salient feature (Gray, 1978, 1981). The depression of motor activity had a short duration, comparable to the anxiogenic effect of FG 7142 in man (Dorow et al., 1983). The effect on dopamine release is seen as a reduction in HVA concentration, measured by voltammetry, in nucleus accumbens but not striatum. Similarly, in drug-injected rats the DOPAC/DA ratio was reduced in nucleus accumbens but not striatum, as compared to vehicleinjected animals. This is in sharp contrast with the effects of stress, which result in an increase in dopamine turnover in nucleus accumbens and frontal cortex but not striatum (Fadda et al., 1978; Lavielle et al., 1978; Trulson and Preussler, 1984; Anderson et al,, 1985). Vehicle-injected rats in the present study also showed increased DOPAC/DA ratios in nucleus accumbens but not striatum following the stress of an intraperitoneal injection (Anderson et al., 1985). The failure of the vehicle injection to produce a comparable increase in HVA levels in the in vivo experiments might be due to the fact that, after surgery, animals had developed resistance to such a mild stress. Our studies show an effect of FG 7142 on dopamine turnover in nucleus accumbens that is similar to the effect of BDZs reported by others (Fadda et al., 1978) and no effect on the striatum. However, Tam and Roth (1985) reported that FG 7142 caused an increase in dopamine turnover in the frontal cortex, an effect opposite to that of BDZs, as well as a decrease in striatum. The decreased nocturnal rise in dopamine turnover in nucleus accumbens returned to control level $2 \mathrm{~d}$ after FG 7142 administration and was followed by a delayed rise. This rise in dopamine turnover was observed with both in vivo and ex vivo methods of measurement.

At present, the mechanism of the effect of FG 7142 on motor activity and dopamine release in nucleus accumbens and striatum is unclear. FG 7142, which has pharmacological and behavioral effects opposite to those of BD7s (Biggio, 1983; Corda et al., 1983; Concas et al., 1984; Pellow and File, 1984; Petersen

Table 3. Effect of FG 7142 on DOPAC/DA ratios in nucleus accumbens and striatum

\begin{tabular}{|c|c|c|c|c|c|c|}
\hline \multirow{2}{*}{$\begin{array}{l}\text { Time after } \\
\text { injection }\end{array}$} & \multicolumn{3}{|c|}{ Nucleus accumbens } & \multicolumn{3}{|l|}{ Striatum } \\
\hline & Vehicle & FG 7142 & $\%$ Change & Vehicle & FG 7142 & $\%$ Change \\
\hline $30 \mathrm{~min}$ & $0.273 \pm 0.036$ & $0.157 \pm 0.051^{\circ}$ & $-47 \pm 17(n=5)$ & $0.197 \perp 0.008$ & $0.197 \perp 0.009$ & $1 \perp 5(n=5)$ \\
\hline $1 \mathrm{hr}$ & $0.168 \pm 0.021$ & $0.103 \pm 0.022^{a}$ & $-39 \pm 12(n=6)$ & $0.177 \pm 0.019$ & $0.167 \pm 0.020$ & $-2 \pm 3(n=5)$ \\
\hline $24 \mathrm{hr}$ & $0.172 \pm 0.035$ & $0.109 \pm 0.028^{a}$ & $-36 \pm 12(n=6)$ & $0.170 \pm 0.016$ & $0.174 \pm 0.007$ & $4 \pm 1(n=5)$ \\
\hline $4 \mathrm{~d}$ & $0.126 \pm 0.016$ & $0.182 \pm 0.025^{a}$ & $47 \pm 19(n=4)$ & - & - & - \\
\hline
\end{tabular}



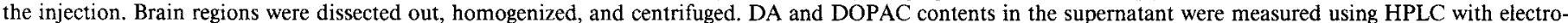
chemical detection. Errors indicate SEMs. ${ }^{a} p<0.05$, compared to vehicle-injected animals. 
Table 4. Blockade by Ro 15-1788 of the acute effect of FG 7142 on DOPAC/DA ratios

DOPAC/DA ratios $30 \mathrm{~min}$ after treatment

\begin{tabular}{|c|c|c|c|c|}
\hline \multirow[b]{2}{*}{ Brain region } & \\
\hline & Vehicle control & FG 7142 & Ro $15-1788$ & $\begin{array}{l}\text { Ro } 15-1788 / \\
\text { FG } 7142\end{array}$ \\
\hline N. accumbens $(n=4)$ & $0.180 \pm 0.009$ & $0.149 \pm 0.010^{a}$ & $0.199 \pm 0.009$ & $0.191 \pm 0.009$ \\
\hline Striatum $(n=4)$ & $0.151 \pm 0.007$ & $0.145 \pm 0.009$ & $0.163 \pm 0.010$ & $0.141 \pm 0.004$ \\
\hline
\end{tabular}

Effect of pretreatment with Ro $15-1788(20 \mathrm{mg} / \mathrm{kg})$ on the acute effect of FG $7142(10 \mathrm{mg} / \mathrm{kg})$ on DOPAC/DA ratios in nucleus accumbens and striatum. Animals were treated in 4 groups: Vehicle Control group $0.5 \mathrm{ml}$ vehicle, i.p., followed after $10 \mathrm{~min}$ by $0.5 \mathrm{ml}$ vehicle, i.p.; FG 7142 group- $0.5 \mathrm{ml}$ vehicle, i.p., followed after $10 \mathrm{~min} \mathrm{by} 10 \mathrm{mg} / \mathrm{kg}$ FG 7142 in $0.5 \mathrm{ml}$ vehicle, i.p.; Ro $15-1788$ group $-20 \mathrm{mg} / \mathrm{kg}$ Ro $15-1788$ in $0.5 \mathrm{ml}$ vehicle, i.p., followed after $10 \mathrm{~min}$ by $0.5 \mathrm{ml}$ vehicle, ip; Ro 15-1788/FG 7142 group-20 mg/kg Ro $15-1788$ in $0.5 \mathrm{ml}$ vehicle, i.p., followed after 10 $\mathrm{min}$ by $10 \mathrm{mg} / \mathrm{kg} \mathrm{FG} 7142 \mathrm{in} 0.5 \mathrm{ml}$ vehicle, i.p. Animals were killed $30 \mathrm{~min}$ after the second injection, brain regions were dissected out, homogenized, and centrifuged. DA and DOPAC contents in the supernatant were measured using HPLC with electrochemical detection. Errors indicate SEMs. ${ }^{a} p<0.05$, compared to values from all other groups.

and Jensen, 1984), when added to membrane preparations of rat cerebral cortex, produces changes in ${ }^{3} \mathrm{H}-\mathrm{GABA}$ binding that are opposite to those produced by diazepam (Biggio et al., 1984). This suggests that whereas BDZs act by enhancing, FG 7142 acts by depressing GABA transmission. Both VTA Al0 and substantia nigra zona compacta dopamine neurons receive inhibitory GABAergic inputs; parallel changes in dopamine release would be expected if a direct action of FG 7142 on these GABAergic inputs was responsible for the effects that we found. However, there are many possible sites of GABA-mediated action for systemically administered FG 7142, since the conneclions of nucleus accumbens include a number of GABAergic steps (Scheel-Krüger, 1986). An action of FG 7142 on several of these could account for both the change in dopamine release and in motor activity. For the long-term effects of FG 7142 there is at present no explanation, but it is interesting to note that Little et al. (1986) described a delayed increase in cortical $\beta$-adrenoreceptor density in mice after a single injection of FG 7142.

Although the mechanism underlying the FG 7142 effects is not clear, the drug provides a useful tool for the investigation of the relation between motor activity and dopamine release in the basal ganglia. The parallel decrease in motor activity and dopamine release in nucleus accumbens would suggest that dopamine release in this region is more tightly coupled to motor activity than it is in the striatum. However, a more detailed analysis using linear regression shows that, during the acute drug effect, dopamine release in nucleus accumbens is not as tightly coupled to motor activity as it is in striatum. Thus, motor activity and dopamine release are not always tightly coupled in either nucleus accumbens or striatum. A study on the effect of light reversal led to the same conclusions (Fillenz and O'Neill, 1986).

Previous studies of the role of dopamine neurons in the basal ganglia in the control of movement have used electrophysiological recordings of single-unit activities in VTA AlO and substantia nigra zona compacta neurons and have found little or no variation in these parameters with movement or during the phases of sleep (Trulson et al., 1981; Miller et al., 1983; Trulson and Preussler, 1984). Furthermore, parallel electrophysiological and voltammetric studies in substantia nigra zona compacta and striatum show that changes in dopamine release in striatum can be independent of the firing rate of nigral dopamine neurons (Trulson, 1985). This suggests that dopamine release in the basal ganglia is not determined solely by impulse frequency, but is also subject to heteroreceptor-mediated presynaptic modulation. The role of presynaptic receptors in the control of dopamine release has been demonstrated in a number of studies with brain slices and synaptosomes (Chesslet, 1984).

In conclusion, neither single-unit discharge of dopaminergic neurons in VTA Al0 or substantia nigra zona compacta nor dopamine release in nucleus accumbens or striatum seems to play a determining role in the control of motor activity.

\section{References}

Anderson, S. M. P., M. Fillenz, and C. Stanford (1985) The effect of chronic, mild stress on monoamine synthesis rate in rat cortical synaptosomes. J. Physiol. (Lond.) 369: 68P

Biggio, G. (1983) The action of stress, $\beta$-carbolines, diazepam and RO 15-1788 on GABA receptors in the rat brain. In Benzodiazepine Recognition Sites Ligands: Biochemistry and Pharmacology, G. Biggio and E. Costa, eds., pp. 105-119, Raven, New York.

Biggio, G., A. Concas, M. Serra, M. Salis, M. G. Corda, V. Nurchi, C. Crisponi, and G. L. Gessa (1984) Stress and $\beta$-carbolines decrease the density of low affinity GABA binding sites; an effect reversed by diazepam. Brain Res. 305: 13-18.

Chesslet, M.-F. (1984) Presynaptic regulation of neurotransmitter release in the brain. Neuroscience 12: 347-375.

Commissiong, J. (1985) Monoamine metabolites: Their relationship and lack of relationship to monoaminergic neuronal activity. Biochem. Pharmacol. 34: 1127-1132.

Concas, A., M. Serra, M. Salis, V. Nurchi, C. Crisponi, and G. Biggio (1984) Evidence for an involvement of GABA receptors in the mediation of the proconvulsant action of ethyl- $\beta$-carboline-3-carboxylate. Neuropharmacology 23: 323-329.

Conrad, L. C. A., and D. W. Pfaff (1976) Autoradiographic tracing of nucleus accumbens efferents in the rat. Brain Res. 113: 589-596.

Corda, M. G., W. D. Baker, W. B. Mendelson, A. Guidotti, and E. Costa (1983) $\beta$-Carbolines enhance shock-induced suppression of drinking in rats. Proc. Natl. Acad. Sci. USA 80: 2072-2076.

Costall, B., R. J. Naylor, J. G. Cannon, and T. Lee (1977) Differentiation of the dopamine mechanisms mediating stereotyped behavior and hyperactivity in the nucleus accumbens and caudato-putamen. J. Pharm. Pharmacol. 29: 337-342.

Costall, B., R. J. Naylor, and V. Nohria (1979) Hyperactivity response to apomorphine and amphetamine in the mouse. The importance of the nucleus accumbens and the caudate-putamen. J. Pharm. Pharmacol. 31: 259-261.

Dahlström, A., and K. Fuxe (1965) Evidence for the existence of monoamine-containing neurons in the central nervous system. I. Demonstration of monoamines in the cell bodies of brain stem neurons. Acta Physiol. Scand. (Suppl. 232) 62: 1-55.

Da Prada, M., H. H. Keller, L. Pieri, R. Kettler, and W. E. Haefely (1984) The pharmacology of Parkinson's disease: Basic aspects and recent advances. Experientia 40: 1165-1172.

Dorow, R., R. Horowski, G. Paschelke, M. Amin, and C. Braestrup 
(1983) Severe anxiety induced by FG 7142, a $\beta$-carboline ligand for benzodiazepine receptors. Lancet 2: 98-99.

Drugan, R. C., S. F. Maier, P. Skolnick, S. M. Paul, and J. N. Crawley (1985) An anxiogenic benzodiazepine receptor ligand induces learned helplessness. Eur. J. Pharmacol. 113: 453-457.

Dunn, A. J., and S. F. File (1983) Cold restraint alters dopamine metabolism in frontal cortex, nucleus accumbens and neostriatum. Physiol. Behav. 31: 511-513.

Fadda, F., R. Argiolas, M. R. Melis, $\Lambda$. H. Tissari, P. L. Onali, and G. L. Gessa (1978) Stress-induced increase in 3,4-dihydroxyphenylacetic acid (DOPAC) levels in the cerebral cortex and in nucleus accumbens: Reversal by diazepam. Life Sci. 23: 2219-2224.

File, S. E., S. Pellow, and C. Braestrup (1985) Effects of the $\beta$-carboline, FG 7142, in the social interaction test of anxiety and the holeboard: Correlations between behavior and plasma concentrations. Pharmacol. Biochem. Behav. 22: 941-944.

Fillenz, M., and R. D. O'Neill (1986) Effects of light reversal on the circadian pattern of motor activity and voltammetric signals recorded in rat forebrain. J. Physiol. (Lond.) 374: 91-101.

Gray, I. A. (1978) The neuropsychology of anxiety. Br. J. Psychol. 69: 417-434.

Gray, J. A. (1981) Anxiety as a paradigm case of emotion. Br. Med. Bull. 37: 193-197.

Groenwegen, H. J., N. E. H. M. Becker, and A. H. M. Lohmann (1980) Subcortical efferents of the nucleus accumbens septi in the cat, studied with retrograde axonal transport of horseradish peroxidase and bisbenzimid. Neuroscience 5: 1903-1916.

Jackson, D. M., N. E. Anden, and A. Dahlström (1975) A functional effect of dopamine in the nucleus accumbens and in some other dopaminergic parts of the brain. Psychopharmacologia 45: 139-149.

Kelley, A. E., and V. B. Domesick (1982) The distribution of the projection from the hippocampal formation to the nucleus accumbens in the rat: An anterograde- and retrograde-horseradish peroxidase study. Neuroscience 7: 2321-2335.

Kelley, A. E., and L. Stinus (1984) The distribution of the projection from the parataenial nucleus of the thalamus to the nucleus accumbens in the rat: An autoradiographic study. Exp. Brain Res. 54: 499512.

Kelly, P. H., P. W. Seviour, and S. D. Iversen (1975) Amphetamine and apomorphine responses in the rat following 6-OHDA lesions of the nucleus accumbens septi and corpus striatum. Brain Res. 94:507_ 522.

König, F. R. J., and R. A. Klippel (1963) The Rat Brain, Williams and Wilkins, Baltimore, MD.

Lavielle, S. L., J. P. Tassin, A. M. Thierry, G. Blanc, D. Herve, C. Barthelemy, and J. Glowinski (1978) Blockade by benzodiazepines of the selective high increase in dopamine turnover induced by stress in mesocortical dopaminergic neurons in the rat. Brain Res. 168: 585594.

Little, H. J. (1986) Benzodiazepine agonists and inverse agonists both decrease locomotor activity and body temperature but show mutual antagonism. Br. J. Pharmacol. 88: 293P.

Little, H. J., S. C. Stanford, and S. C. Taylor (1986) $\beta$-Adrenoceptor upregulation after FG 7142 is abolished by chronic treatment with the antidepressant desmethylimipramine. Br. J. Pharmacol. 89: 800P.

Makanjuda, R. O. A., and G. W. Ashcroft (1982) Behavioral effects of electrolytic and 6-hydroxydopamine lesions of the caudate putamen nuclei. Psychopharmacology 76: 333-340.

Makanjuda, R. O. A., R. C. Dow, and G. W. Ashcroft (1980) Behavioral responses to stereotaxically controlled injections of monoamine neurotransmitters into the accumbens and caudate-putamen nuclei. Psychopharmacology 71:227-235.

Marsden, C. A. (1984) Measurement of Neurotransmitter Release In Vivo. IBRO Handbook Series: Methods in the Neurosciences, vol. 6, Wiley-Interscience, New York.

McGeer, E. G., W. A. Staines, and P. L. McGeer (1984) Neurotransmitters in the basal ganglia. Can. J. Neurol. Sci. (Suppl. 1) 11: 8999.

Miller, J. D., J. Farber, P. Gatz, H. Roffwarg, and D. C. German (1983) Activity of mesencephalic dopamine and non-dopamine neurons across stages of sleep and waking in the rat. Brain Res. 273: 133-141.

Mogenson, G. J., and C. Y. Yim (1981) Electrophysiological and neuropharmacological-behavioral studies of the nucleus accumbens: Implications for its role as a limbic-motor interface. In The Neurobiology of Nucleus Accumbens, R. B. Chronister and J. F. De France, eds., pp. 210-229, Haer Institute for Electrophysiological Research, Brunswick, ME.

Mueller, K., R. Palmour, C. D. Andrews, and P. I. Knott (1985) In vivo voltammetric evidence of production of uric acid by rat caudate. Brain Res. 335: 231-235.

Nauta, W. J. H., G. P. Smith, R. L. M. Faull, and V. B. Domesick (1978) Efferent connections and nigral afferents to nucleus accumbens septi in the rat. Neuroscience 3: 385-401.

Neill, D. B., and J. B. Justice (1981) An hypothesis for a behavioral function of dopaminergic transmission in nucleus accumbens. In The Neurobiology of Nucleus Accumbens, R. B. Chronister and J. F. De France, eds., pp. 343-350, Haer Institute for Electrophysiological Research, Brunswick, ME.

O'Neill, R. D., and M. Fillenz (1985a) Detection of homovanillic acid in vivo using microcomputer-controlled voltammetry: Simultaneous monitoring of rat motor activity and striatal dopamine release. Neuroscience 14: 753-763.

O'Neill, R. D., and M. Fillenz (1985b) Simultaneous monitoring of dopamine release in rat frontal cortex, nucleus accumbens and striatum: Effect of drugs, circadian changes and correlations with motor activity. Neuroscience $16: 49-55$.

O’Neill, R. D., R. A. Grünewald, M. Fillenz, and W. J. Albery (1982) Lincar sweep voltammetry with carbon-paste electrodes in the rat striatum. Neuroscience 7: 1945-1954.

O'Neill, R. D., M. Fillenz, and W. J. Albery (1983a) The development of linear sweep voltammetry with carbon paste electrodes in vivo. J. Neurosci. Methods 8: 263-273.

O'Neill, R. D., M. Fillenz, W. J. Albery, and N. J. Goddard (1983b) The monitoring of ascorbate and monoamine transmitter metabolites using microprocessor-controlled voltammetry. Neuroscience 90: 8793.

O'Neill, R. D., R. A. Grünewald, M. Fillenz, and W. J. Albery (1983c) The effect of unilateral cortical lesions on the circadian changes in rat striatal ascorbate and homovanillic acid levels measured in vivo using voltammetry. Neurosci. Lett. 42: 105-1 10.

O'Neill, R. D., M. Fillenz, R. A. Grünewald, M. R. Bloomfield, W. J. Albcry, C. M. Jamicson, J. H. Williams, and J. A. Gray (1984) Voltammetric carbon-paste electrodes monitor uric acid and not 5HIAA at the 5-hydroxyindole potential in the rat brain. Neurosci. Lett. 45: 39-46.

Pellow, S., and S. File (1984) Multiple sites of action for anxiogenic drugs: Behavioral, electrophysiological and biochemical correlations. Psychopharmacology 83: 304-315.

Petersen, E. N., and L. H. Jensen (1984) Proconflict effect of benzodiazepine receptor inverse agonists and other inhibitors of GABA function. Eur. J. Pharmacol. 103: 91-97.

Pijnenburg, A. J. J., W. M. M. Honig, and J. M. Van Rossum (1975) Antagonism of apomorphine- and $d$-amphetamine-induced locomotor activity by injection of haloperidol into the nucleus accumbens of the rat. Psychopharmacologia 41: 87-95.

Pijnenburg, A. J. J., W. M. M. Honig, J. A. M. Van der Heyden (1976) Effects of chemical stimulation of the mesolimbic dopamine system upon locomotor activity. Eur. J. Pharmacol. 35: 49-58.

Powell, E. W., and R. B. Leman (1976) Connections of the nucleus accumbens. Brain Res. 105: 389-403.

Scheel-Krüger, J. (1986) Dopamine-GABA interactions: Evidence that GABA transmits, modulates and mediates dopaminergic functions in the basal ganglia and the limbic system. Acta Neurol. Scand. (Suppl. 107) 73: 9-54.

Swanson, L. W., and W. M. Cowan (1973) A note on the connections and development of the nucleus accumbens. Brain Res. 92: 324-330.

Swanson, L. W., and W. M. Cowan (1977) An autoradiographic study of the organisation of the efferent connections of the hippocampal formation in the rat. J. Comp. Neurol. 172: 49-84.

Tam, S.-Y., and R. H. Roth (1985) Selective increase in dopamine metabolism in the prefrontal cortex by the anxiogenic $\beta$-carboline FG 7142. Biochem. Pharmacol. 34: 1595-1598.

Trulson, M. E. (1985) Simultaneous recording of substantia nigra neurons and voltammetric release of dopamine in the caudate of behaving cats. Brain Res. Bull. 15: 221-223.

Trulson, M. E., and D. W. Preussler (1984) Dopamine containing ventral tegmental area neurons in freely moving cats: Activity during the sleep-waking cycle and effects of stress. Exp. Neurol. 83: 367377.

Trulson, M. E., D. W. Preussler, and G. A. Howell (1981) Activity of 
substantia nigra units across the sleep-waking cycle in freely moving cats. Neurosci. Lett. 26: 183-188.

Ungerstedt, O. (1971) Stereotaxic mapping of the monoamine pathways in the brain. Acta Physiol. Scand. (Suppl. 367) 82: 1-48.

Watanabe, H. (1984) Activation of dopamine synthesis in mesolimbic dopamine neurons by immobilization stress in the rat. Neuropharmacology 23: 1335-1338.

Westerink, B. H. C., and J. Korf (1975) Influence of drugs on striatal and limbic homovanillic acid concentration in the rat brain. Eur. $\mathbf{J}$. Pharmacol. 33: 31-40.
Westerink, B. H. C., and J. Korf (1976) Regional rat brain levels of 3,4-dihydroxyphenylacetic acid and homovanillic acid: Concurrent fluorimetric measurement and influence of drugs. Eur. J. Pharmacol. 38: 281-291.

Westerink, B. H. C., and R. J. Krickert (1986) Effect of various centrally acting drugs on the efflux of dopamine metabolites from the rat brain. J. Neurochem. 46: 1145-1152.

Williams, D. J., A. R. Grossmann, and P. Slater (1977) The efferent projections of the nucleus accumbens in the rat. Brain Res. 130:217227. 